\title{
Dietary patterns and bone mineral status in young adults: the Northern Ireland Young Hearts Project
}

\author{
Claire R. Whittle ${ }^{1}$, Jayne V. Woodside ${ }^{1}$, Chris R. Cardwell ${ }^{1}$, Hannah J. McCourt ${ }^{1}$, Ian S. Young ${ }^{1}$, \\ Liam J. Murray ${ }^{1}$, Colin A. Boreham ${ }^{2}$, Alison M. Gallagher ${ }^{3}$, Charlotte E. Neville ${ }^{1}$ and \\ Michelle C. McKinley ${ }^{1 *}$ \\ ${ }^{1}$ School of Medicine, Dentistry and Biomedical Sciences, Centre for Public Health, Queen's University Belfast, \\ Grosvenor Road, Belfast BT12 6BJ, UK \\ ${ }^{2}$ Institute for Sport and Health, University College Dublin, Dublin, Republic of Ireland \\ ${ }^{3}$ Northern Ireland Centre for Food and Health (NICHE), University of Ulster, Coleraine BT52 1SA, UK
}

(Submitted 11 March 2011 - Final revision received 9 November 2011 - Accepted 10 November 2011 - First published online 4 January 2012)

\begin{abstract}
Studies of individual nutrients or foods have revealed much about dietary influences on bone. Multiple food or nutrient approaches, such as dietary pattern analysis, could offer further insight but research is limited and largely confined to older adults. We examined the relationship between dietary patterns, obtained by a posteriori and a priori methods, and bone mineral status (BMS; collective term for bone mineral content (BMC) and bone mineral density (BMD)) in young adults (20-25 years; $n$ 489). Diet was assessed by $7 \mathrm{~d}$ diet history and BMD and BMC were determined at the lumbar spine and femoral neck (FN). A posteriori dietary patterns were derived using principal component analysis (PCA) and three a priori dietary quality scores were applied (dietary diversity score (DDS), nutritional risk score and Mediterranean diet score). For the PCA-derived dietary patterns, women in the top compared to the bottom fifth of the 'Nuts and Meat' pattern had greater FN BMD by $0.074 \mathrm{~g} / \mathrm{cm}^{2}(P=0.049)$ and FN BMC by $0.40 \mathrm{~g}(P=0.034)$ after adjustment for confounders. Similarly, men in the top compared to the bottom fifth of the 'Refined' pattern had lower FN BMC by 0.41g ( $P=0 \cdot 049)$. For the $a$ priori DDS, women in the top compared to the bottom third had lower FN BMD by $0.05 \mathrm{~g} / \mathrm{cm}^{2}$ after adjustments $(P=0.052)$, but no other relationships with BMS were identified. In conclusion, adherence to a 'Nuts and Meat' dietary pattern may be associated with greater BMS in young women and a 'Refined' dietary pattern may be detrimental for bone health in young men.
\end{abstract}

\section{Key words: Dietary patterns: Bone mineral status: Principal component analysis: Dietary quality scores}

Peak bone mass is reached in young adulthood and is influenced by genetics ${ }^{(1,2)}$ as well as modifiable lifestyle factors, such as adequate nutrition ${ }^{(3-5)}$. Hence, dietary behaviours during adolescence and young adulthood may have important consequences for peak bone mass attainment and future fracture risk. The relationship between diet and bone health has mainly focused on individual nutrients, particularly calcium and/or vitamin $\mathrm{D}^{(6-8)}$, with beneficial effects also indicated for other dietary components including fruit and vegetables $^{(9-12)}$. This approach has revealed a great deal about dietary influences on bone health, but it is possible that broader multiple food or nutrient approaches may offer further insight. Dietary pattern analysis has become popular within nutritional epidemiology ${ }^{(13)}$ as it may better account for the cumulative and interactive effects of foods and nutrients within the diet and is proposed to better reflect realworld dietary intake in relation to biomarkers of disease ${ }^{(14-16)}$.

Two different approaches, namely a posteriori ${ }^{(15)}$ and a priori $^{(16)}$, have been developed for exploring dietary patterns. A posteriori methods, such as factor analysis, are statistical exploratory post hoc techniques that use information from dietary records to aggregate variables into factors representing common underlying patterns of food consumption within a population. Relationships between the derived dietary patterns and biomarkers of disease can then be examined. $A$ priori methods such as the healthy eating index ${ }^{(16)}$ and Mediterranean diet score (MDS) ${ }^{(17,18)}$ explore data using pre-defined diet quality scores, generally based on existing knowledge about what constitutes a healthy diet. Research investigating dietary patterns and bone mineral status

Abbreviations: BMC, bone mineral content; BMD, bone mineral density; BMS, bone mineral status; DDS, dietary diversity score; FN, femoral neck; LS, lumbar spine; MDS, Mediterranean diet score; NRS, nutritional risk score; PCA, principal component analysis; YH, Young Hearts. 
(BMS; collective term used for bone mineral content (BMC) and bone mineral density (BMD)) is limited ${ }^{(19-26)}$. Previous cross-sectional research applying a posteriori methods has indicated positive associations between 'Prudent', 'Healthy' or 'Nutrient dense' type dietary patterns and BMD in older men and women $^{(19)}$, premenopausal ${ }^{(20)}$ and postmenopausal women $^{(23,25)}$, younger men ${ }^{(21)}$, and young children ${ }^{(26)}$ and inverse associations with a dietary pattern high in confectionery in men and women ${ }^{(19)}$ and a Western-type pattern in pre- ${ }^{(20)}$ and postmenopausal women ${ }^{(23,25)}$. Very recently, results from a retrospective cohort study indicated an overall reduced risk of fracture in men and women aged $\geq 50$ years in association with a 'Nutrient dense' dietary pattern rich in vegetables, fruit and whole grains, using factor analysis ${ }^{(24)}$. To date, only one study has applied both $a$ posteriori and a priori methods in an investigation of diet and bone health ${ }^{(24)}$. Adherence to an a posteriori dietary pattern with some features from the Mediterranean diet was positively associated with total body BMC and lumbar spine (LS) BMD in Greek women; however, no association was observed with the a priori $\mathrm{MDS}^{(24)}$.

Given the limited research to date in relation to dietary patterns and bone, and the fact that the majority of the existing literature is limited to older adults, the aim of this research is to examine the relationship between dietary patterns and bone health in young adults using both a posteriori and a priori methods.

\section{Methods}

\section{Study population}

The present study was conducted as part of an ongoing longitudinal study called the Young Hearts Project (YH) which was originally designed to examine CVD risk factors in adolescents. Detailed methodology has been described elsewhere $^{(27,28)}$. Briefly, boys and girls aged 12 and 15 years, from Northern Ireland ( $n$ 1015), were recruited from postprimary schools between 1989 and 1990 (YH1), which resulted in a $2 \%$ representative population of Northern Ireland schoolchildren. In 1992 and 1993, 455 of the former 12-year-olds participated in a second screening (YH2). All children from the original cohort (YH1) were invited to participate in a follow-up study between October 1997 and October $1999(\mathrm{YH} 3)^{(28)}$, when they were aged between 20 and 25 years. The response rate for $\mathrm{YH} 3$ was $48.2 \%$ ( $n$ 489). This study was conducted according to the guidelines laid down in the Declaration of Helsinki and all procedures involving human subjects were approved by the Research Ethics Committee of Queen's University Belfast. Written informed consent was obtained from all participants. The present paper is based on dietary data and BMD measurements from YH3.

\section{Anthropometry, dietary assessment and other relevant data collection}

In brief, height and weight measurements were carried out on each of the subjects, while wearing light-weight clothing and no shoes, from which BMI was calculated. Dietary data were collected in the form of a $7 \mathrm{~d}$ diet history ${ }^{(29)}$. The portion size of foods and beverages consumed was estimated by means of photographs of known portion weights of foods supplemented with the use of common household cups, glasses and dishes. Estimates of energy and nutrient intakes from food and beverages were calculated using a computerised dietary analysis programme based on the UK food composition tables (WISP; Tinuviel Software). Physical activity was quantified using a modified version of the validated Baecke questionnaire of habitual physical activity $(30,31)$ Information on smoking status (current, former, never) was collected by questionnaire and father's socio-economic status at YH1 was used as an indicator of social class. More detailed information on the relevant data collection has been described elsewhere ${ }^{(28)}$.

\section{Assessment of bone mineral density}

BMD and BMC were measured at the LS (position L2-L4) and femoral neck (FN) by dual-energy X-ray absorptiometry using a Lunar Expert-XL bone densitometer (Lunar Corporation). This densitometer has a precision of $1.0 \%$ in vivo and $0.5 \% \mathrm{in}$ vitro. Before each scan, the densitometer was calibrated by a qualified radiographer according to the manufacturer's instructions. The results from the scan were expressed as BMC in grams of calcium hydroxyapatite, and BMD in $g$ of calcium hydroxyapatite $/ \mathrm{cm}^{2}$. Scans of women were undertaken within $10 \mathrm{~d}$ of commencement of their last menstrual period.

\section{A posteriori dietary patterns - principal component analysis}

Over 1000 individual foods were identified from the diet histories. These foods were manually aggregated into thirty-one food groups categorised generally by types of foods or macronutrient content (e.g. fruit, fats, red meat), to perform food dietary analysis with the use of principal component analysis (PCA; Table S1, supplementary material for this article can be found at http://www.journals.cambridge.org/bjn). PCA reduced the food groups into a smaller number of underlying factors or dietary patterns that could explain variations in dietary intake; the number of factors, or dietary patterns, retained was based on a combination of food group components with an eigenvalue $>1$ and examination of the break-point in the scree plot ${ }^{(14)}$. The factors were rotated by an orthogonal transformation with the varimax option which maintains uncorrelated factors and produces a simpler structure with easier interpretability ${ }^{(32)}$. Food groups with a factor loading greater than $0 \cdot 2$ on a component were considered informative in describing the dietary patterns. The factor score for each pattern was calculated by taking the sum of the observed intakes of the food-group items weighted by factor loading, resulting in each subject having a factor score for each pattern. Subject scores were then categorised into quintiles for each of the four dietary patterns, with quintile 5 conforming most closely to that particular diet. Owing to known sex differences in bone metabolism, dietary pattern analysis was conducted separately for men and women ${ }^{(21)}$. 


\section{A priori dietary scores}

Numerous a priori dietary indices have been designed as a dietary assessment method, either against a particular healthy diet or for the purpose of disease prevention ${ }^{(33)}$. The three a priori dietary scores chosen for this analysis were: the dietary diversity score (DDS) which is a simple food-group-based score and is relatively easy to perform within a large cohort $^{(34)}$; the MDS which is based on a whole dietary pattern that is known to be associated with reduced concentrations of CVD risk biomarkers ${ }^{(35)}$ and a reduced risk of CVD mortality and morbidity ${ }^{(18,36)}$; and finally, the nutritional risk score $(\mathrm{NRS})^{(37-39)}$ which is a nutrient-based ranking index corresponding to the intake of nineteen individual nutrients.

\section{Dietary diversity score}

To create the DDS ${ }^{(34)}$, the 1098 individual foods reported in the $7 \mathrm{~d}$ diet histories were condensed into five groups: dairy, meat, grain, fruit and vegetable. Foods were grouped based on similarities in nutrient composition and uses in the diet. The score was calculated by counting the number of foods consumed in these food groups daily, which was in the range of $0-5$ for each subject. This score was calculated for each of the $7 \mathrm{~d}$ of the week and a daily average calculated. A minimum threshold was assigned for each of the food groups to avoid credit for consumption of small amounts of the food groups, as pre-defined by Kant et $a l .{ }^{(34)}$. To gain a diversity score for consumption of meat, fruit and vegetables, $30 \mathrm{~g}$ of solid foods and $60 \mathrm{~g}$ of liquids needed to be consumed. For dairy and grain, a minimum of $15 \mathrm{~g}$ of solids and $30 \mathrm{~g}$ of liquids were required. Mixed dishes with food components meeting the threshold amount contributed one point to the score.

\section{Mediterranean diet score}

The MDS is a scale that measures adherence to the traditional Mediterranean diet. The original scale was based on the intake of eight items ${ }^{(17)}$, which was later revised to incorporate the consumption of fish ${ }^{(18)}$. A value of 0 or 1 was assigned to each of the nine components, of which the maximum MDS could be 9, therefore indicating the greatest adherence to the traditional Mediterranean diet. Sex-specific median cutoffs were calculated for each of the food component groups. For food components with a beneficial effect (high intake of vegetables, legumes, fruits and nuts, cereal and fish), a value of 0 was assigned to those subjects whose daily consumption was above the median. For food components which are considered less beneficial/desirable (high meat and meat products and dairy), subjects whose consumption was above the median were assigned a value of 0 . To assess fat intake, a ratio of monounsaturated fats to saturated fats was used and a value of 1 was assigned to those who had consumption that was above the median. For men, a value of 1 was assigned if the subject consumed between 10 and $50 \mathrm{~g}$ of alcohol; and likewise for women, if the consumption was between 5 and $25 \mathrm{~g}$ daily.

\section{Nutritional risk score}

This is a validated risk score for assessing diet quality based on a nineteen-nutrient index ${ }^{(37-39)}$. The score was calculated by ranking the mean nutrient intakes (from the $7 \mathrm{~d}$ diet history) from 1 to 489 for all subjects. A lower score was assigned to those with the most desirable nutrient intake level, e.g. low fat or high micronutrient intake, whereas a higher rank was assigned to those with a less desirable nutrient intake level, e.g. high fat or lower micronutrient intake. However, for ease of comparison with the MDS and DDS (in each case, higher scores represent a more optimal diet), we transformed the NRS so that the higher score also corresponded to the most desirable diet. The NRS was calculated for the following: energy, protein, total fat, monounsaturated and saturated fats, alcohol, cholesterol, $\mathrm{Na}$, carbohydrate, polyunsaturated fat, fibre, $\mathrm{Ca}$, Se, vitamins $\mathrm{C}, \mathrm{B}_{6}, \mathrm{~B}_{12}$ and $\mathrm{E}$, folate and $\beta$-carotene. An overall nutrient risk score was then calculated from the sum of all the individual nineteen-nutrient risk scores.

\section{Statistical analyses}

All statistical analyses were performed using Statistical Package for Social Sciences (SPSS version 17.0; SPSS for Windows, SPSS, Inc.). Sample means and frequencies were calculated separately for men and women. Each of the dietary patterns derived from PCA (i.e. Healthy, Traditional, Refined, Nuts and Meat, and Social) and each of the dietary scores (i.e. DDS, NRS and MDS) were grouped into quintiles and tertiles, respectively. Continuous variables are presented as means and standard deviations and categorical variables as absolute frequencies and percentages. When examining the general subject characteristics, continuous variables were compared using linear regression in quintile or tertile groupings. Categorical data were examined using $\chi^{2}$ tests for trends. Multivariate linear regression analysis was used to assess the relationship between the dietary pattern scores (in quintiles or tertiles) and BMD and BMC. Data were presented for unadjusted and adjusted models controlling for common confounding factors known to influence bone health (age, BMI, smoking status, physical activity, socio-economic status and energy intake). Data for adjusted models (adjusted mean and 95\% CI) are presented in tables only where adjustment has influenced the corresponding $P$ value. No adjustments for multiple comparisons were made.

\section{Results}

The general health and lifestyle characteristics and dietary intake data of the participants stratified by sex are presented in Table 1. Factor loadings, which represent correlation coefficients between food groups and dietary patterns, for the derived dietary patterns are presented in Tables 2 and 3 for men and women, respectively. The patterns were named according to the food groups that had high loadings (positive or negative). Four patterns were identified for men ('Healthy', 'Traditional', 'Refined' and 'Social') and four were identified for women ('Healthy', 'Traditional', 'Nuts and Meat' and 
Table 1. General health and lifestyle characteristics and dietary intakes in men and women participating in Young Hearts 3

(Mean values and standard deviations; number of subjects and percentages)

\begin{tabular}{|c|c|c|c|c|c|}
\hline & \multicolumn{2}{|c|}{ Males $(n 251)$} & \multicolumn{2}{|c|}{ Females ( $n$ 238) } & \multirow[b]{2}{*}{$P^{*}$} \\
\hline & Mean & SD & Mean & SD & \\
\hline Age (years) & $22 \cdot 4$ & 1.6 & $22 \cdot 8$ & 1.7 & 0.014 \\
\hline Height $(\mathrm{cm})$ & 177.9 & 6.72 & 164.4 & $6 \cdot 2$ & $\leq 0.001$ \\
\hline Weight (kg) & $75 \cdot 4$ & $11 \cdot 6$ & 64.5 & 11.9 & $\leq 0.001$ \\
\hline $\mathrm{BMI}\left(\mathrm{kg} / \mathrm{m}^{2}\right)$ & $23 \cdot 8$ & 3.2 & 23.8 & 4.3 & 0.860 \\
\hline \multicolumn{6}{|l|}{ Smoking status $(n, \%) \dagger$} \\
\hline Current & 92 & 36.9 & 86 & $36 \cdot 1$ & 0.893 \\
\hline Former & 22 & $8 \cdot 8$ & 24 & $10 \cdot 1$ & \\
\hline Never & 135 & $54 \cdot 2$ & 128 & $53 \cdot 8$ & \\
\hline Smoking (pack-years) & 3.6 & $6 \cdot 2$ & $2 \cdot 3$ & 4.4 & 0.019 \\
\hline Age started smoking (years) & $15 \cdot 6$ & $2 \cdot 5$ & $15 \cdot 6$ & $2 \cdot 6$ & 0.926 \\
\hline Age at menarche (years) & & & $12 \cdot 8$ & 1.4 & \\
\hline Vegetarian( $n, \%)$ & 3 & 1.2 & 14 & 5.9 & $\leq 0.001$ \\
\hline PASł & 7.96 & 1.39 & 7.41 & $1 \cdot 20$ & $\leq 0.001$ \\
\hline LS BMD $\left(\mathrm{g} / \mathrm{cm}^{2}\right)$ & $1 \cdot 248$ & 0.142 & 1.188 & 0.119 & $\leq 0.001$ \\
\hline FN BMD $\left(\mathrm{g} / \mathrm{cm}^{2}\right)$ & $1 \cdot 145$ & 0.169 & 1.053 & 0.146 & $\leq 0.001$ \\
\hline LS BMC $(\mathrm{g})$ & $62 \cdot 71$ & 10.48 & $51 \cdot 26$ & 8.69 & $\leq 0.001$ \\
\hline FN BMC $(\mathrm{g})$ & $6 \cdot 19$ & 0.95 & 4.84 & 0.71 & $\leq 0.001$ \\
\hline Energy intake (MJ) & $13 \cdot 14$ & 3.60 & 8.40 & $2 \cdot 46$ & $\leq 0.001$ \\
\hline Protein intake (\% of energy) & $13 \cdot 1$ & 2.4 & $14 \cdot 0$ & 3.0 & 0.001 \\
\hline Total fat intake (\% of energy) & $32 \cdot 6$ & $5 \cdot 6$ & 33.0 & $6 \cdot 0$ & 0.380 \\
\hline Carbohydrate intake ( $\%$ of energy) & 47.5 & 7.5 & $51 \cdot 1$ & $6 \cdot 8$ & $\leq 0.001$ \\
\hline Ca intake (mg) & 1149 & 465 & 735 & 283 & $\leq 0.001$ \\
\hline Vitamin D intake $(\mu \mathrm{g})$ & 2.3 & 1.6 & 1.8 & 1.9 & $\leq 0.001$ \\
\hline
\end{tabular}

PAS, physical activity score; LS, lumbar spine; BMD, bone mineral density; FN, femoral neck; BMC, bone mineral content.

${ }^{*}$ Means and SD for continuous variables or number and percentage for categorical variables were analysed using an independent $t$-test or $\chi^{2}$ test.

† Data missing for $n 2$ males.

$\ddagger$ Physical activity was quantified using a modified version of the validated Baecke questionnaire of habitual physical activity ${ }^{(30,31)}$.

'Social'). The 'Healthy' dietary pattern had high positive loadings for fruit, vegetables, brown bread, rice and pasta and negative loadings for white bread, chips and meat dishes. The 'Traditional' dietary pattern loaded highly for white bread, fats and hot drinks and loaded negatively for soft drinks. The 'Social' dietary pattern loaded highly for alcohol. The 'Refined' dietary pattern (men) had high loadings for puddings, crisps, chips, confectionery, chocolate and soft drinks. The 'Nuts and Meat' pattern (women) had high positive loadings for nuts, chocolate, red meat, meat dishes and poultry. These dietary patterns together accounted for 29.4 and $28.0 \%$ of the total variance in the original food groups in men and women, respectively. In men, the contribution for each dietary pattern was: healthy $9.4 \%$; traditional 7.7\%; refined $6.7 \%$ and social $5.6 \%$. The contributions were similar for women: healthy $9.3 \%$; traditional $7.4 \%$; nuts and meat $5.9 \%$ and social $5.4 \%$.

Of the subjects who participated in the present study, $51.3 \%$ were men and $48.7 \%$ were women. The average age for men and women was 22.4 and $22 \cdot 8$ years, respectively. The mean for each of the three dietary scores is as follows: men DDS 2.1 (SD 0.4, range 1.0-3.0), NRS 126.0 (SD 19.5, range 43.4-169.7), MDS 3.7 (SD 0.9, range 0.8-6.0); and women DDS 2.0 (SD 0.4, range 1.0-2.9), NRS $119 \cdot 5$ (SD 19.5, range 48.7-163.7), MDS 3.7 (SD 0.9, range $1 \cdot 1-6 \cdot 1$ ). The NRS was significantly higher in men compared to women $(P \leq 0 \cdot 001)$, but there was no significant difference between males and females for the DDS or MDS.

The general characteristics of the study subjects were compared across PCA quintiles and a priori dietary score tertiles using linear regression analysis (Tables S2 and S3, supplementary material for this article can be found at http://www. journals.cambridge.org/bjn). No significant differences were observed for age, height, weight or BMI for the various PCA-derived dietary patterns or a priori dietary scores, with the exception of height in men categorised by MDS $(P=0.008)$. As indicated in the Supplementary Tables, there was some variation in smoking status, physical activity and socio-economic status across the dietary patterns, notably for the 'Healthy', 'Traditional' and 'Social' dietary patterns and for the NRS and MDS, but not the DDS.

Table 4 shows BMD and BMC for the a posteriori PCAderived dietary patterns in quintiles for men and women. Using linear regression, no significant difference was observed in LS BMD across the different PCA-derived dietary patterns in men or women. For FN BMD, only one association was apparent; women with higher scores in the 'Nuts and Meat' dietary pattern had significantly greater FN BMD after adjusting for common confounding factors. This relationship remained significant after further adjustment for mean energy intake. In terms of LS BMC, no significant relationship was observed in men or women in any dietary pattern at this site. In relation 
Table 2. Factor loading* matrix for men ( $n$ 251) participating in Young Hearts 3

\begin{tabular}{|c|c|c|c|c|}
\hline & \multicolumn{4}{|c|}{ Dietary pattern } \\
\hline & Factor 1: Healthy & Factor 2: Traditional & Factor 3: Refined & Factor 4: Social \\
\hline Fruit & 0.665 & - & - & 0.242 \\
\hline Vegetables & 0.508 & - & - & 0.437 \\
\hline Brown bread & 0.568 & - & - & - \\
\hline White bread & -0.401 & 0.530 & 0.221 & 0.324 \\
\hline Rice and pasta & 0.346 & -0.238 & - & 0.553 \\
\hline Pizza & - & -0.230 & - & - \\
\hline Chips & -0.393 & - & 0.530 & - \\
\hline Potatoes & - & 0.382 & - & - \\
\hline Soup & - & - & - & - \\
\hline Fats & - & 0.685 & - & 0.264 \\
\hline Cheese & - & - & - & 0.425 \\
\hline Eggs and egg dishes & - & - & - & 0.430 \\
\hline Meat dishes & -0.365 & - & 0.257 & - \\
\hline Red meat & - & 0.398 & - & - \\
\hline Poultry & - & -0.272 & - & - \\
\hline Fatty fish & - & - & - & - \\
\hline White fish & - & - & - & 0.436 \\
\hline Breakfast cereals & 0.545 & 0.258 & - & \\
\hline Alcohol & -0.379 & - & - & 0.444 \\
\hline Soft drinks & - & -0.480 & 0.451 & 0.255 \\
\hline Hot drinks & - & 0.516 & -0.352 & - \\
\hline Milk & 0.379 & - & - & - \\
\hline Yoghurts & 0.350 & - & - & - \\
\hline Biscuits and cakes & - & 0.212 & - & - \\
\hline Chocolate & - & - & 0.505 & -0.286 \\
\hline Confectionery & - & - & 0.477 & - \\
\hline Crisps & -0.311 & - & 0.440 & - \\
\hline Nuts & - & - & - & 0.250 \\
\hline Puddings & 0.249 & - & 0.540 & - \\
\hline Sugar and preserves & - & 0.604 & - & - \\
\hline Condiments & - & - & 0.516 & 0.249 \\
\hline
\end{tabular}

* Only food groups with factor loadings $>0.2$ were included.

to FN BMC, higher 'Refined' group scores were associated with lower FN BMC in men and 'Nuts and Meat' scores were associated with higher FN BMC in women, even after adjustment. Moreover, a greater adherence to a 'Social' dietary pattern was associated with increased FN BMC in men. However, this relationship diminished after further adjustment for mean energy intake.

Table 5 shows BMD and BMC for each of the a priori dietary scores in tertiles. No statistically significant association was observed between LS BMD and any of the dietary quality indices for men or women. However, a significant linear trend towards increased FN BMD was observed in women, but not men with increasing DDS, which weakened following adjustment for mean energy intake. No relationships were observed between LS BMC or FN BMC and any of the a priori dietary scores for men or women.

The analyses presented in Tables 4 and 5 were repeated following removal of the bottom $10 \%$ of under-reporters (based on the ratio of energy intake to BMR) in the sample. This did not affect the results described previously for the a priori data. For the a posteriori data, the final adjusted $P$ value for the relationship between FN BMC and the 'Refined' dietary pattern was $P=0.084$ (compared to $P=0.048$ before removal of under-reporters) (data not shown).

\section{Discussion}

This study uniquely examined the relationship between BMS, a posteriori PCA-derived dietary patterns and a priori dietary scores in younger adults. For women, the 'Nuts and Meat' dietary pattern was associated with greater FN BMD and FN BMC in unadjusted and adjusted analyses; also women with the highest DDS had greater FN BMD. For men, a 'Refined' dietary pattern was associated with lower FN BMC after adjustment but no other relationships were apparent. No strong associations were identified with any of the $a$ priori dietary scores in males and BMD or BMC. However, a significant trend towards greater FN BMD with increasing DDS was observed in women, but this trend weakened following adjustment for energy intake. To date, relatively few papers have examined the relationship between dietary patterns and BMS. The Framingham Osteoporosis Study, using cluster analysis, reported lower FN BMD in elderly men in association with the 'Candy cluster $^{(19)}$; this is similar to our observation in younger men for the 'Refined' PCA dietary pattern. The energy-dense foods loaded in our 'Refined' dietary pattern are comparable to the foods in the 'Candy cluster' from the Framingham cohort ${ }^{(19)}$, this suggesting that a diet rich in refined foods and lacking in nutrient-dense foods may be detrimental to bone health in men. For women, a 'Nuts and Meat' dietary 
Table 3. Factor loading* matrix for women $(n$ 238) participating in Young Hearts 3

\begin{tabular}{|c|c|c|c|c|}
\hline & \multicolumn{4}{|c|}{ Dietary pattern } \\
\hline & Factor 1: Healthy & Factor 2: Traditional & Factor 3: Nuts and Meat & Factor 4: Socia \\
\hline Fruit & 0.700 & - & - & - \\
\hline Vegetables & 0.423 & 0.240 & - & 0.319 \\
\hline Brown bread & 0.619 & - & - & - \\
\hline White bread & -0.602 & 0.349 & - & - \\
\hline Rice and pasta & - & - & - & 0.438 \\
\hline Pizza & - & - & - & 0.324 \\
\hline Chips & -0.439 & -0.278 & 0.321 & - \\
\hline Potatoes & - & - & - & - \\
\hline Soup & - & - & - & - \\
\hline Fats & -0.277 & 0.485 & - & - \\
\hline Cheese & - & 0.383 & - & 0.200 \\
\hline Eggs and egg dishes & - & - & - & -0.285 \\
\hline Meat dishes & -0.319 & - & 0.372 & - \\
\hline Red meat & - & - & 0.299 & - \\
\hline Poultry & - & - & 0.337 & - \\
\hline Fatty fish & - & - & - & - \\
\hline White fish & 0.325 & - & - & - \\
\hline Breakfast cereals & 0.233 & 0.433 & - & - \\
\hline Alcohol & - & - & - & 0.649 \\
\hline Soft drinks & - & -0.496 & 0.238 & 0.360 \\
\hline Hot drinks & - & 0.672 & - & - \\
\hline Milk & - & 0.692 & - & - \\
\hline Yoghurts & 0.399 & - & - & - \\
\hline Biscuits and cakes & - & - & 0.262 & -0.403 \\
\hline Chocolate & - & - & 0.525 & - \\
\hline Confectionery & - & - & 0.344 & - \\
\hline Crisps & -0.314 & -0.339 & 0.424 & 0.358 \\
\hline Nuts & - & - & 0.603 & - \\
\hline Puddings & - & - & 0.309 & -0.381 \\
\hline Sugar and preserves & -0.291 & 0.374 & - & -0.452 \\
\hline Condiments & - & 0.256 & 0.398 & - \\
\hline
\end{tabular}

* Only food groups with factor loadings $>0.2$ were included.

pattern was associated with greater $\mathrm{FN}$ BMC and BMC; a similar, albeit non-significant, relationship was observed in a sub-analysis of younger Canadian women (aged 25-49 years), who adhered to a dietary pattern that loaded highly for nuts, meat and meat products. Nuts and meat are high in protein, suggesting that increased protein intake may be beneficial to BMS in women. Protein is one of the main components of the bone matrix; however, the relationship between dietary protein and bone health is controversial. Some have suggested that diets high in protein (in particular from animal sources) are detrimental to bone health ${ }^{(40-42)}$. However, a recent meta-analysis concluded that protein intake reduces bone resorption markers and has a small positive association with $\mathrm{BMD}$ and $\mathrm{BMC}^{(43)}$. In support of this, Scottish postmenopausal women adhering to a dietary pattern high in processed foods had lower LS and FN BMD, which the authors explained could be due to a characteristically low-protein diet ${ }^{(25)}$. Nuts have been suggested to be beneficial to bone accrual in healthy young men ${ }^{(44)}$ and can decrease bone resorption ${ }^{(45)}$, thus indicating a potential contribution of such foods to the greater BMD and BMC observed here in women. In this context, five dietary pattern studies have reported positive associations between BMD and a healthy dietary pattern, in men aged 25-49 years ${ }^{(21)}$, premenopausal $^{(20)}$ and postmenopausal women ${ }^{(23,25)}$ and the elderly ${ }^{(19)}$. A similar association was only apparent as a non-significant trend for young men in this study. Interestingly, Hardcastle et al. ${ }^{(25)}$ also observed decreased bone resorption in those adhering to a healthy dietary pattern.

In relation to a priori dietary quality scores, many of the existing a priori diet scores have been defined mainly on current available evidence regarding the association between diet and CVD; to our knowledge, there are currently no bonespecific a priori scores available. Of the pre-existing indices, only one other ${ }^{(24)}$ has investigated the association between the MDS and bone health and, consistent with this analysis, they found no significant association between the MDS and BMS. Interestingly, these authors also applied PCA to their data to derive dietary patterns and found that a PCA-derived dietary pattern that had features of the Mediterranean diet (rich in fish and olive oil and low in meat and meat products) was positively associated with LS BMD and total body BMC. As discussed by the authors ${ }^{(24)}$, the lack of association with the a priori MDS is perhaps not surprising, as it does not positively rate some dietary elements that are regarded as bone-sparing foods, such as dairy products. On the other hand, a greater intake of grain and legume foods is scored as beneficial within the MDS; however, these food groups can be acid-producing, and thus potentially distorting the acid-base balance in the bone ${ }^{(46)}$. Also, the a priori MDS was originally 
Table 4. Bone mineral density (BMD) and bone mineral content (BMC) for the quintiles (Q) group of four food patterns determined by a posteriori principal component analysis (PCA) related to men and women participating in Young Hearts (YH) 3

(Mean values and standard deviations; adjusted mean values and $95 \%$ confidence intervals)

\begin{tabular}{|c|c|c|c|c|c|c|c|c|c|c|c|c|}
\hline & \multicolumn{2}{|c|}{ Q1 } & \multicolumn{2}{|c|}{ Q2 } & \multicolumn{2}{|c|}{ Q3 } & \multicolumn{2}{|c|}{ Q4 } & \multicolumn{2}{|c|}{ Q5 } & \multirow[b]{2}{*}{$P^{*}$} & \multirow[b]{2}{*}{$R^{2}$} \\
\hline & Mean & SD & Mean & SD & Mean & SD & Mean & SD & Mean & SD & & \\
\hline \multicolumn{13}{|l|}{ Males } \\
\hline \multicolumn{13}{|l|}{ Factor 1: Healthy } \\
\hline LS BMD $\left(\mathrm{g} / \mathrm{cm}^{2}\right)$ & 1.220 & 0.159 & 1.239 & 0.138 & $1 \cdot 267$ & 0.150 & 1.263 & 0.133 & 1.251 & 0.132 & 0.184 & 0.003 \\
\hline FN BMD $\left(\mathrm{g} / \mathrm{cm}^{2}\right)$ & 1.121 & 0.171 & $1 \cdot 143$ & 0.170 & $1 \cdot 156$ & $0 \cdot 187$ & $1 \cdot 132$ & 0.152 & $1 \cdot 132$ & 0.152 & 0.537 & 0.003 \\
\hline LS BMC $(\mathrm{g})$ & $61 \cdot 27$ & $10 \cdot 10$ & 59.87 & 11.55 & 65.33 & $10 \cdot 37$ & 63.90 & 9.54 & 62.95 & $10 \cdot 24$ & 0.117 & 0.006 \\
\hline FN BMC $(\mathrm{g})$ & 6.06 & 0.99 & $6 \cdot 34$ & 1.06 & $6 \cdot 12$ & 0.95 & $6 \cdot 12$ & 0.88 & $6 \cdot 20$ & 0.89 & 0.435 & 0.002 \\
\hline Factor 2: Traditional & & & & & & & & & & & & \\
\hline LS BMD $\left(\mathrm{g} / \mathrm{cm}^{2}\right)$ & 1.239 & 0.154 & 1.266 & 0.168 & 1.232 & 0.134 & 1.235 & 0.122 & 1.270 & 0.133 & 0.637 & 0.003 \\
\hline FN BMD $\left(\mathrm{g} / \mathrm{cm}^{2}\right)$ & 1.125 & 0.168 & $1 \cdot 175$ & 0.199 & $1 \cdot 130$ & 0.152 & $1 \cdot 123$ & 0.166 & $1 \cdot 171$ & 0.160 & 0.607 & 0.002 \\
\hline LS BMC $(\mathrm{g})$ & 62.34 & 9.37 & 63.82 & 11.60 & $62 \cdot 13$ & $9 \cdot 32$ & 61.52 & 12.50 & 63.45 & 9.33 & 0.967 & 0.004 \\
\hline FN BMC $(\mathrm{g})$ & 6.04 & 0.92 & 6.34 & 1.06 & $6 \cdot 12$ & 0.95 & $6 \cdot 12$ & 0.88 & $6 \cdot 32$ & 0.92 & 0.435 & 0.002 \\
\hline Factor 3: Refined & & & & & & & & & & & & \\
\hline LS BMD $\left(\mathrm{g} / \mathrm{cm}^{2}\right)$ & 1.259 & 0.133 & 1.255 & 0.163 & $1 \cdot 211$ & 0.131 & 1.264 & 0.137 & 1.249 & 0.145 & 0.856 & 0.004 \\
\hline FN BMD $\left(\mathrm{g} / \mathrm{cm}^{2}\right)$ & 1.139 & 0.149 & $1 \cdot 170$ & 0.198 & 1.105 & 0.162 & $1 \cdot 162$ & 0.173 & $1 \cdot 143$ & 0.163 & 0.970 & 0.004 \\
\hline LS BMC $(\mathrm{g})$ & $62 \cdot 19$ & 9.91 & $64 \cdot 39$ & 10.76 & $60 \cdot 73$ & 9.58 & 62.42 & 12.06 & 63.29 & 10.07 & 0.969 & 0.004 \\
\hline FN BMC $(\mathrm{g})$ & $6 \cdot 18$ & 0.90 & 6.32 & 1.00 & 5.93 & 0.93 & 6.31 & 1.02 & $6 \cdot 15$ & 0.86 & 0.892 & 0.004 \\
\hline Adjusted $\dagger$ & & & & & & & & & & & 0.623 & 0.166 \\
\hline Mean & -0.3 & 5 & $\begin{array}{r}0 \\
-0.0\end{array}$ & 6 & $\begin{array}{r}- \\
-0.4\end{array}$ & 12 & $\begin{array}{r}0 \\
-0.1\end{array}$ & 0.56 & Refe & ence & & \\
\hline Further adjustedf & & & & & & & & & & & 0.049 & 0.187 \\
\hline Mean & & & & & & & & & Refe & ence & & \\
\hline $95 \% \mathrm{Cl}$ & 0.0 & 0.83 & 0.17 & 0.96 & -0.2 & 0.46 & -0.0 & 0.68 & & & & \\
\hline Factor 4: Social & & & & & & & & & & & & \\
\hline LS BMD $\left(\mathrm{g} / \mathrm{cm}^{2}\right)$ & 1.235 & 0.147 & 1.243 & 0.155 & 1.256 & 0.134 & 1.228 & 0.132 & 1.278 & 0.145 & 0.283 & 0.001 \\
\hline FN BMD $\left(\mathrm{g} / \mathrm{cm}^{2}\right)$ & 1.124 & 0.168 & 1.135 & 0.170 & 1.144 & 0.178 & 1.127 & 0.159 & 1.191 & 0.172 & 0.107 & 0.007 \\
\hline LS BMC (g) & $62 \cdot 35$ & 11.27 & 61.87 & $10 \cdot 34$ & $62 \cdot 81$ & $9 \cdot 13$ & $61 \cdot 16$ & $10 \cdot 88$ & 65.03 & 10.67 & 0.333 & 0 \\
\hline FN BMC $(\mathrm{g})$ & 6.04 & 0.96 & $6 \cdot 10$ & 0.88 & 6.22 & 1.03 & 6.05 & 0.91 & $6 \cdot 51$ & 0.92 & 0.043 & 0.013 \\
\hline Adjusted $\dagger$ & & & & & & & & & & & 0.046 & 0.179 \\
\hline Mean & & & & & & & & & Refe & ence & & \\
\hline $95 \% \mathrm{Cl}$ & -0.8 & -0.09 & -0.74 & -0.05 & -0.5 & 0.15 & -0.75 & -0.06 & & & & \\
\hline Further adjustedł & & & & & & & & & & & 0.158 & 0.180 \\
\hline Mean & & & & & & & & & Refe & ence & & \\
\hline $95 \% \mathrm{Cl}$ & -0.7 & 0.02 & -0.7 & 0.03 & -0.54 & -0.19 & -0.7 & 0.00 & & & & \\
\hline Females & & & & & & & & & & & & \\
\hline Factor 1: Healthy & & & & & & & & & & & & \\
\hline LS BMD $\left(\mathrm{g} / \mathrm{cm}^{2}\right)$ & 1.193 & 0.124 & $1 \cdot 169$ & 0.115 & $1 \cdot 177$ & 0.126 & $1 \cdot 181$ & 0.132 & $1 \cdot 219$ & 0.090 & 0.295 & 0 \\
\hline FN BMD $\left(\mathrm{g} / \mathrm{cm}^{2}\right)$ & 1.045 & 0.134 & 1.072 & 0.179 & 1.036 & 0.133 & 1.084 & 0.150 & 1.026 & 0.126 & 0.757 & 0.004 \\
\hline LS BMC $(\mathrm{g})$ & 52.77 & 8.69 & 49.03 & 8.91 & 50.73 & 8.41 & 51.00 & 9.34 & 52.79 & 7.83 & 0.652 & 0.004 \\
\hline FN BMC $(\mathrm{g})$ & 4.84 & 0.72 & 4.86 & 0.80 & 4.74 & 0.60 & 4.93 & 0.77 & 4.83 & 0.66 & 0.797 & 0.005 \\
\hline Factor 2: Traditional & & & & & & & & & & & & \\
\hline LS BMD $\left(\mathrm{g} / \mathrm{cm}^{2}\right)$ & 1.179 & 0.112 & 1.194 & 0.105 & 1.189 & 0.124 & 1.172 & 0.143 & 1.205 & 0.103 & 0.601 & 0.003 \\
\hline FN BMD $\left(\mathrm{g} / \mathrm{cm}^{2}\right)$ & 1.057 & 0.180 & 1.031 & 0.129 & 1.065 & 0.129 & 1.026 & 0.156 & 1.084 & 0.125 & 0.541 & 0.003 \\
\hline LS BMC (g) & 51.97 & 8.44 & $50 \cdot 90$ & $9 \cdot 31$ & 51.05 & 8.44 & $50 \cdot 60$ & 9.59 & $51 \cdot 80$ & 7.91 & 0.867 & 0.005 \\
\hline FN BMC $(\mathrm{g})$ & 4.91 & 0.89 & 4.75 & 0.65 & 4.82 & 0.68 & 4.72 & 0.64 & 5.03 & 0.65 & 0.567 & 0.003 \\
\hline Factor 3: Nuts & & & & & & & & & & & & \\
\hline LS BMD $\left(\mathrm{g} / \mathrm{cm}^{2}\right)$ & 1.178 & 0.132 & $1 \cdot 172$ & 0.108 & $1 \cdot 216$ & 0.107 & $1 \cdot 164$ & 0.122 & $1 \cdot 211$ & 0.118 & 0.329 & 0 \\
\hline FN BMD $\left(\mathrm{g} / \mathrm{cm}^{2}\right)$ & 1.009 & 0.148 & 1.060 & 0.128 & 1.075 & 0.155 & 1.050 & 0.134 & 1.073 & 0.159 & 0.094 & 0.009 \\
\hline Adjusted $t$ & & & & & & & & & & & 0.026 & 0.078 \\
\hline Mean & & 081 & -0 & 026 & & & -0 & 029 & Refe & ence & & \\
\hline $95 \% \mathrm{C}$ & -0.14 & -0.019 & -0.08 & 0.036 & -0.08 & 0.038 & -0.09 & 0.033 & & & & \\
\hline Further adjustedł & & & & & & & & & & & 0.049 & 0.076 \\
\hline Mean & & & & 017 & & & -0 & & Refe & ence & & \\
\hline $95 \% \mathrm{Cl}$ & -0.13 & -0.012 & -0.08 & 0.048 & -0.08 & 0.046 & -0.08 & 0.035 & & & & \\
\hline LS BMC $(\mathrm{g})$ & $51 \cdot 15$ & 8.62 & 49.59 & 8.43 & 52.19 & 8.05 & 50.68 & 9.07 & 52.83 & 9.36 & 0.318 & 0 \\
\hline FN BMC $(\mathrm{g})$ & 4.67 & 0.71 & 4.84 & 0.58 & 4.98 & 0.78 & 4.77 & 0.59 & 4.98 & 0.85 & 0.104 & 0.008 \\
\hline Adjusted $\dagger$ & & & & & & & & & & & 0.017 & 0.145 \\
\hline Mean & & & & & & & - & & Refe & ence & & \\
\hline $95 \% \mathrm{Cl}$ & -0.7 & -0.14 & -0.5 &, 0.04 & -0.4 & 0.16 & -0.5 & 0.05 & & & & \\
\hline Further adjustedł & & & & & & & & & & & 0.034 & 0.144 \\
\hline Mean & & & & 20 & & & & & Refe & ence & & \\
\hline $95 \% \mathrm{Cl}$ & -0.6 & -0.11 & -0.5 & 0.11 & -0.4 & 0.19 & -0.5 & 0.06 & & & & \\
\hline Factor 4: Social & & & & & & & & & & & & \\
\hline LS BMD $\left(\mathrm{g} / \mathrm{cm}^{2}\right)$ & 1.166 & 0.106 & $1 \cdot 190$ & $1 \cdot 201$ & $1 \cdot 175$ & 0.125 & $1 \cdot 207$ & 0.115 & 1.199 & 0.125 & 0.161 & 0.005 \\
\hline FN BMD $\left(\mathrm{g} / \mathrm{cm}^{2}\right)$ & 1.055 & 0.144 & 1.046 & 0.171 & 1.063 & 0.134 & 1.047 & 0.146 & 1.053 & 0.136 & 0.965 & 0.005 \\
\hline LS BMC (g) & 50.95 & 8.06 & 50.78 & $8 \cdot 14$ & $50 \cdot 18$ & $8 \cdot 10$ & 52.00 & 9.05 & 52.40 & $10 \cdot 11$ & 0.331 & 0 \\
\hline FN BMC $(\mathrm{g})$ & 4.89 & 0.69 & 4.79 & 0.75 & 4.83 & 0.65 & 4.83 & 0.69 & 4.88 & 0.80 & 0.925 & 0.005 \\
\hline
\end{tabular}

LS, lumbar spine; FN, femoral neck.

*Data analysed using linear regression (unadjusted, adjusted and further adjusted as described) with bone mineral site as the outcome and dietary patterns in quintiles as a continuous variable.

†Adjusted for age, BMI, smoking, physical activity and father's social class at YH1.

$\ddagger$ Further adjusted for mean energy intake (MJ). 
Table 5. Bone mineral density (BMD) and bone mineral content $(B M C)$ for the tertile $(T)$ groups using three different a priori dietary score systems in men and women participating in Young Hearts (YH) 3

(Mean values and standard deviations; adjusted mean values and $95 \%$ confidence intervals)

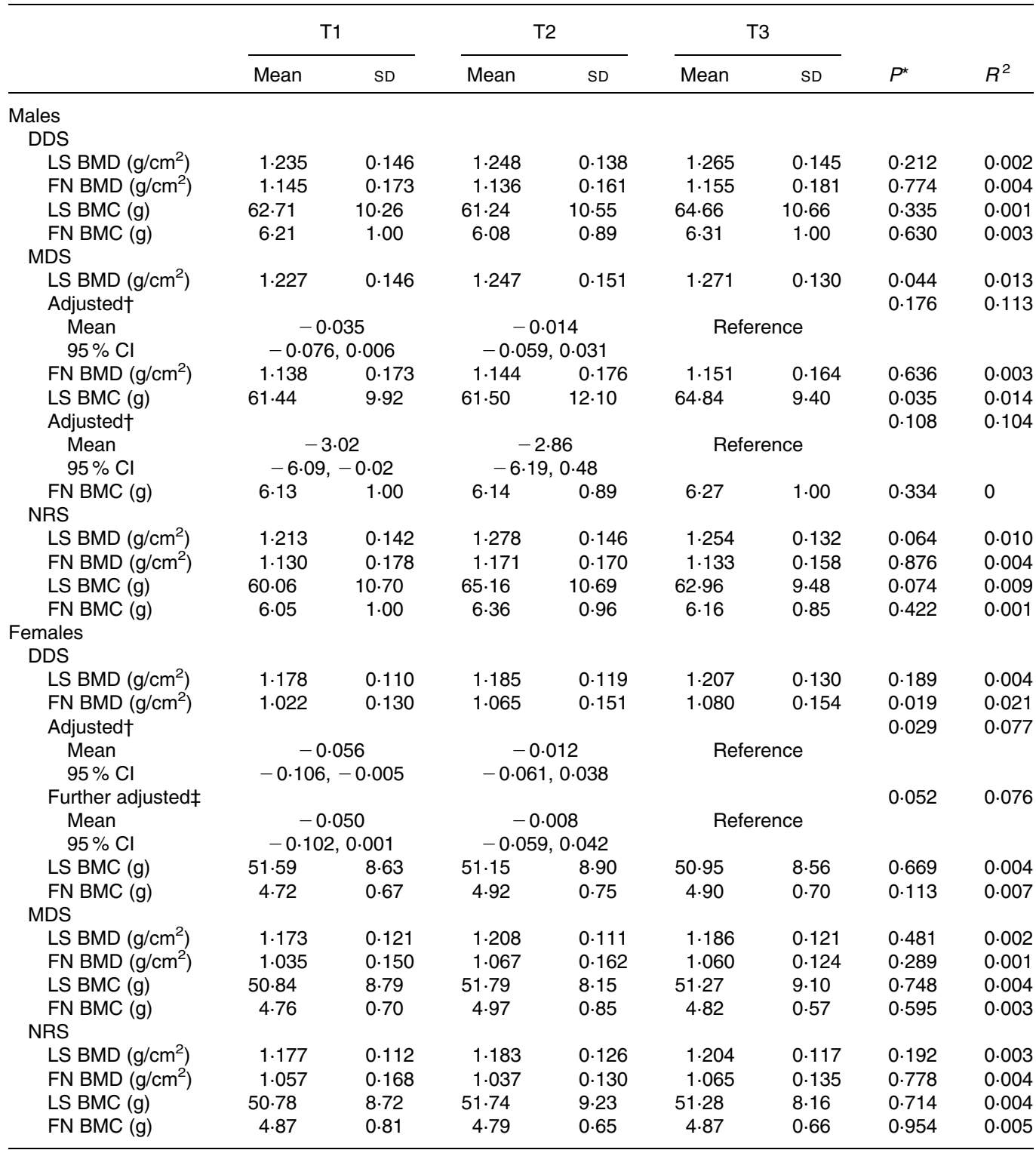

LS, lumbar spine; FN, femoral neck.

* Data analysed using linear regression (unadjusted, adjusted and further adjusted as described) with bone mineral site as the outcome and dietary patterns in tertiles as a continuous variable.

† Adjusted for age, BMI, smoking, physical activity and father's social class at $\mathrm{YH} 1$.

¥ Further adjusted for mean energy intake (MJ).

based on the dietary habits of a Southern European population $^{(17,18)}$ but, in this instance, has been applied to a young Northern European population. The maximum score achievable using the MDS is 9; however, the maximum MDS achieved in the present study was only 6. This limited spread in the data may, in turn, have limited the likelihood of identifying a relationship with BMS.

In the YH studies, BMD was measured at the 'gold standard' sites for osteoporosis diagnosis and future fracture prediction $^{(47)}$. Others have measured peripheral sites, such as the forearm ${ }^{(20)}$ which have the benefit of being quick and easy to measure but may not be as useful as prognostic indicators. It was also possible to adjust for many other factors known to influence BMS in this analysis. Alongside these strengths, the study limitations must also be acknowledged. The results presented are based on a cross-sectional analysis, and thus, a temporal relationship cannot be inferred; further cross-sectional and prospective cohort studies will help to provide further insight into the relationships observed here. Genetics and early environment play a strong role in the development of peak bone mass ${ }^{(48)}$, which we were unable to control for. Our sample size, while comparable to other 
studies in this field ${ }^{(20,23,24,26)}$, was modest and may have had an impact on the ability of this investigation to detect significant relationships with BMS. Finally, there is the possibility of detecting associations by chance (type I error) as a result of the number of comparisons made. A Bonferroni correction for multiple comparisons was not applied, as this remains a controversial statistical adjustment ${ }^{(49)}$ and one that is not routinely applied in the dietary pattern literature. The results of this study should be reviewed with this in mind.

The strengths and limitations of PCA have been discussed by others ${ }^{(15,50-52)}$. The main limitation is the many decisions made by researchers during the PCA process, such as the consolidation of food items into food groups, choosing the number of components to be retained, selecting the method of rotation, naming the factors and categorisation of the data for statistical analysis. In this study, dietary assessment was via a $7 \mathrm{~d}$ diet history in a face-to-face interview with a nutritionist, which is a robust dietary assessment method in nutritional epidemiology ${ }^{(53)}$. The most commonly used method of dietary assessment in dietary pattern analysis has been the FFQ and $\mathrm{Hu}$ et al. $^{(50)}$ reported that FFQ are valid in this context in terms of the reproducibility of the dietary patterns produced. Diet histories have not been as extensively used for this purpose, and therefore their validity is not well established; however, Slattery et $a l .{ }^{(54)}$ and Hu et al. ${ }^{(50)}$ successfully used this method. One of the foremost subjective decisionmaking steps in dietary pattern analysis is condensing food items into a smaller, more manageable number of food group variables. When using the diet history, this means that approximately $800-1000$ individual foods will be reduced to usually less than fifty food groups. The same process using an FFQ requires less condensing and so fewer decisions on behalf of the investigator at this stage in the process. Although the validity of diet histories in this context has not been formally investigated, McNaughton et al. ${ }^{(55)}$ investigated the ability of a $5 \mathrm{~d}$ food diary compared to a 48 and $24 \mathrm{~h}$ recall to effectively characterise dietary patterns. They found the $5 \mathrm{~d}$ food diary and $48 \mathrm{~h}$ recall to be superior to a single $24 \mathrm{~h}$ recall in identifying dietary patterns in a British cohort ( $n$ 2265). More recently, dietary patterns identified using a $3 \mathrm{~d}$ food diary were found to be relatively similar to those identified with an FFQ in adolescents ${ }^{(56)}$. In relation to categorising the PCA data for statistical analysis, no consistent split or categorisation is apparent in the field; tertiles, quartiles and quintiles are all employed. Data are presented in quintiles in the present study, which may have resulted in a statistical advantage in terms of maximising the chances of detecting significant associations.

In conclusion, little is known about the relationship between a posteriori PCA-derived dietary patterns and $a$ priori dietary quality scores and BMS, particularly in young adults. This research indicates that PCA-derived dietary patterns with high factor loadings for red meat, meat dishes, poultry, vegetables and nuts may be associated with greater BMS in young women and that a refined dietary pattern may be detrimental for bone health in young men. Significant relationships were not apparent between the a priori dietary scores used in the present study and BMS. The development of bone-specific a priori scores may be a useful tool in nutritional epidemiology and also for public health practitioners. Further studies of this nature will help to further characterise the relationship between dietary patterns and bone health in different population groups.

\section{Acknowledgements}

The Northern Ireland Young Hearts Project (YH3) was funded by the Wellcome Trust and the British Heart Foundation. L. J. M., A. M. G. and C. A. B. were primarily responsible for the conception of the Young Hearts project, development of the overall research plan and study oversight. A. M. G. and C. E. N. conducted the dietary assessment and data collection. C. R. W., H. J. M., M. C. M., C. E. N. and J. V. W. prepared the data set for dietary pattern assessment, completed the statistical analysis and interpreted the resultant data. C. R. C. advised on statistical analysis and assisted with the interpretation of the data. C. R. W. and M. C. M. drafted the manuscript, and all other authors contributed to editing and proof reading of the final version of the manuscript. M. C. M., the corresponding author, had the primary responsibility for the final content. All authors declare that they have no conflicts of interest.

\section{References}

1. Gueguen R, Jouanny P, Guillemin F, et al. (1995) Segregation analysis and variance components analysis of bone mineral density in healthy families. J Bone Miner Res 10, 2017-2022.

2. Slemenda CW, Christian JC, Williams CJ, et al. (1991) Genetic determinants of bone mass in adult women: a reevaluation of the twin model and the potential importance of gene interaction on heritability estimates. J Bone Miner Res $\mathbf{6}$, 561-567.

3. Bonjour J, Chevalley T, Rizzoli R, et al. (2007) Geneenvironment interactions in the skeletal response to nutrition and exercise during growth. Med Sport Sci 51, 64-80.

4. Bonjour J, Gueguen L, Palacios C, et al. (2009) Minerals and vitamins in bone health: the potential value of dietary enhancement. Br J Nutr 101, 1581-1596.

5. Javaid MK \& Cooper C (2002) Prenatal and childhood influences on osteoporosis. Best Pract Res Clin Endocrinol Metab 16, 349-367.

6. Bischoff-Ferrari HA, Dawson-Hughes B, Baron JA, et al. (2007) Calcium intake and hip fracture risk in men and women: a meta-analysis of prospective cohort studies and randomized controlled trials. Am J Clin Nutr 86, 1780-1790.

7. Tang BMP, Eslick GD, Nowson C, et al. (2007) Use of calcium or calcium in combination with vitamin D supplementation to prevent fractures and bone loss in people aged 50 years and older: a meta-analysis. Lancet 370, 657-666.

8. DIPART (Vitamin D Individual Patient Analysis of Randomized Trials) Group (2010) Patient level pooled analysis of 68500 patients from seven major vitamin D fracture trials in US and Europe. BMJ 340, b5463.

9. Tucker KL, Hannan MT, Chen H, et al. (1999) Potassium, magnesium, and fruit and vegetable intakes are associated with greater bone mineral density in elderly men and women. Am J Clin Nutr 69, 727-736.

10. New SA, Bolton-Smith C, Grubb DA, et al. (1997) Nutritional influences on bone mineral density: a cross-sectional study in premenopausal women. Am J Clin Nutr 65, 1831-1839. 
11. New SA, Robins SP, Campbell MK, et al. (2000) Dietary influences on bone mass and bone metabolism: further evidence of a positive link between fruit and vegetable consumption and bone health? Am J Clin Nutr 71, 142-151.

12. Braam LAJLM, Knapen MHJ, Geusens P, et al. (2003) Vitamin $\mathrm{K}_{1}$ supplementation retards bone loss in postmenopausal women between 50 and 60 years of age. Calcif Tissue Int 73, 21-26.

13. Hu FB (2002) Dietary pattern analysis: a new direction in nutritional epidemiology. Curr Opin Lipidol 13, 3-9.

14. Hu FB, Rimm EB, Stampfer MJ, et al. (2000) Prospective study of major dietary patterns and risk of coronary heart disease in men. Am J Clin Nutr 72, 912-921.

15. Newby PK \& Tucker KL (2004) Empirically derived eating patterns using factor or cluster analysis: a review. Nutr Rev 62, 177-203.

16. Kennedy ET, Ohls J, Carlson S, et al. (1995) The Healthy Eating Index: design and applications. J Am Diet Assoc 95, $1103-1108$

17. Trichopoulou A, Kouris-Blazos A, Wahlqvist ML, et al. (1995) Diet and overall survival in elderly people. BMJ 311, 1457-1460.

18. Trichopoulou A, Costacou T, Bamia C, et al. (2003) Adherence to a Mediterranean diet and survival in a Greek population. $N$ Engl J Med 348, 2599-2608.

19. Tucker KL, Chen H, Hannan MT, et al. (2002) Bone mineral density and dietary patterns in older adults: the Framingham Osteoporosis Study. Am J Clin Nutr 76, 245-252.

20. Okubo H, Sasaki S, Horiguchi H, et al. (2006) Dietary patterns associated with bone mineral density in premenopausal Japanese farmwomen. Am J Clin Nutr 83, 1185-1192.

21. Langsetmo L, Poliquin S, Hanley DA, et al. (2010) Dietary patterns in Canadian men and women ages 25 and older: relationship to demographics, body mass index, and bone mineral density. BMC Musculoskelet Disord 11, 20.

22. Langsetmo L, Hanley DA, Prior JC, et al. (2011) Dietary patterns and incident low-trauma fractures in postmenopausal women and men aged $\geq 50 \mathrm{y}$ : a population-based cohort study. Am J Clin Nutr 93, 192-199.

23. Sugiura M, Nakamura M, Ogawa K, et al. (2011) Dietary patterns of antioxidant vitamin and carotenoid intake associated with bone mineral density: findings from post-menopausal Japanese female subjects. Osteoporos Int 22, 143-152.

24. Kontogianni MD, Melistas L, Yannakoulia M, et al. (2009) Association between dietary patterns and indices of bone mass in a sample of Mediterranean women. Nutrition 25 , $165-171$.

25. Hardcastle AC, Aucott L, Fraser WD, et al. (2011) Dietary patterns, bone resorption and bone mineral density in early post-menopausal Scottish women. Eur J Clin Nutr $\mathbf{6 5}$, $378-385$.

26. Wosje KS, Khoury PR, Claytor RP, et al. (2010) Dietary patterns associated with fat and bone mass in young children. Am J Clin Nutr 92, 294-303.

27. Boreham C, Savage JM, Primrose D, et al. (1993) Coronary risk factors in schoolchildren. Arch Dis Child 68, 182-186.

28. Gallagher AM, Savage JM, Murray LJ, et al. (2002) A longitudinal study through adolescence to adulthood: the Young Hearts Project, Northern Ireland. Public Health 116, $332-340$.

29. van Staveren WA, de Boer JO \& Burema J (1985) Validity and reproducibility of a dietary history method estimating the usual food intake during one month. Am J Clin Nutr $\mathbf{4 2}$, $554-559$.
30. Montoye HJ, Kemper HCG, Saris WHM, et al. (1996) Measuring Physical Activity and Energy Expenditutre, 1st ed. Champaign, IL: Human Kinetics.

31. Pereira MA, FitzerGerald SJ, Gregg EW, et al. (1997) A collection of Physical Activity Questionnaires for health-related research. Med Sci Sports Exerc 29, S1-S205.

32. Costello AB \& Osborne JW (2005) Best practices in exploratory factor analysis: four recommendations for getting the most from your analysis. PARE 10, 1-9.

33. Waijers PM, Feskens EJ \& Ocke MC (2007) A critical review of predefined diet quality scores. Br J Nutr 97, 219-231.

34. Kant AK, Schatzkin A, Harris TB, et al. (1993) Dietary diversity and subsequent mortality in the First National Health and Nutrition Examination Survey Epidemiologic Follow-up Study. Am J Clin Nutr 57, 434-440.

35. Estruch R, Martinez-Gonzalez MA, Corella D, et al. (2006) Effects of a Mediterranean-style diet on cardiovascular risk factors: a randomized trial. Ann Intern Med 145, 1-11.

36. Knoops KT, de Groot LC, Kromhout D, et al. (2004) Mediterranean diet, lifestyle factors, and 10-year mortality in elderly European men and women: the HALE project. JAMA 292, 1433-1439.

37. Millen BE, Pencina MJ, Kimokoti RW, et al. (2006) Nutritional risk and the metabolic syndrome in women: opportunities for preventive intervention from the Framingham Nutrition Study. Am J Clin Nutr 84, 434-441.

38. Millen BE, Quatromoni PA, Copenhafer DL, et al. (2001) Validation of a dietary pattern approach for evaluating nutritional risk: the Framingham Nutrition Studies. $J$ Am Diet Assoc 101, 187-194.

39. Quatromoni PA, Copenhafer DL, Demissie S, et al. (2002) The internal validity of a dietary pattern analysis. The Framingham Nutrition Studies. J Epidemiol Community Health 56, 381-388.

40. Feskanich D, Willett WC, Stampfer MJ, et al. (1996) Protein consumption and bone fractures in women. Am J Epidemiol 143, 472-479.

41. Frassetto LA, Todd KM, Morris RC, et al. (2000) Worldwide incidence of hip fracture in elderly women: relation to consumption of animal and vegetable foods. J Gerontol A Biol Sci Med Sci 55, M585-M592.

42. Sellmeyer DE, Stone KL, Sebastian A, et al. (2001) A high ratio of dietary animal to vegetable protein increases the rate of bone loss and the risk of fracture in postmenopausal women. Study of Osteoporotic Fractures Research Group. Am J Clin Nutr 73, 118-122.

43. Darling AL, Millward DJ, Torgerson DJ, et al. (2009) Dietary protein and bone health: a systematic review and metaanalysis. Am J Clin Nutr 90, 1674-1692.

44. Hogstrom M, Nordstrom P \& Nordstrom A (2007) n-3 Fatty acids are positively associated with peak bone mineral density and bone accrual in healthy men: the NO2 Study. Am J Clin Nutr 85, 803-807.

45. Salari Sharif P, Asalforoush M, Ameri F, et al. (2010) The effect of $n-3$ fatty acids on bone biomarkers in Iranian postmenopausal osteoporotic women: a randomized clinical trial. Age (Dordr) 32, 179-186.

46. New SA (2003) Acid-base homeostasis and the skeleton: is there a fruit and vegetable link to bone health? In Nutritional Aspects of Bone Health, pp. 291-311 [SA New and JP Bonjour, editors]. London: Royal Society of Chemistry.

47. Hans D, Downs RW Jr, Duboeuf F, et al. (2006) Skeletal sites for osteoporosis diagnosis: the 2005 ISCD Official Positions. J Clin Densitom 9, 15-21. 
48. Brown LB, Streeten EA, Shapiro JR, et al. (2005) Genetic and environmental influences on bone mineral density in preand post-menopausal women. Osteoporos Int 16, 1849-1856.

49. Perneger TV (1998) What's wrong with Bonferroni adjustments? BMJ 316, 1236-1238.

50. Hu FB, Rimm E, Smith-Warner SA, et al. (1999) Reproducibility and validity of dietary patterns assessed with a foodfrequency questionnaire. Am J Clin Nutr 69, 243-249.

51. Schulze MB \& Hoffmann K (2006) Methodological approaches to study dietary patterns in relation to risk of coronary heart disease and stroke. Br J Nutr 95, 860-869.

52. Martinez ME, Marshall JR \& Sechrest L (1998) Invited Commentary: factor analysis and the search for objectivity. Am J Epidemiol 148, 17-19.
53. Livingstone MB, Prentice AM, Coward WA, et al. (1992) Validation of estimates of energy intake by weighed dietary record and diet history in children and adolescents. Am J Clin Nutr 56, 29-35.

54. Slattery ML, Boucher KM, Caan BJ, et al. (1998) Eating patterns and risk of colon cancer. Am J Epidemiol 148, $4-16$.

55. McNaughton SA, Mishra GD, Bramwell G, et al. (2005) Comparability of dietary patterns assessed by multiple dietary assessment methods: results from the 1946 British Birth Cohort. Eur J Clin Nutr 59, 341-352.

56. Ambrosini GL, O'Sullivan TA, de Klerk NH, et al. (2011) Relative validity of adolescent dietary patterns: a comparison of a FFQ and $3 \mathrm{~d}$ food record. Br J Nutr 105, 625-633. 